Genij Ortopedii. 2021. Vol. 27, no. 5. P. 592-596.

Original article

https://doi.org/10.18019/1028-4427-2021-27-5-592-596

\title{
New option of tibial plateau plasty in total knee arthroplasty
}

\author{
I.F. Akhtyamov ${ }^{1}$, I.Sh. Gilmutdinov ${ }^{1,2}$, E.R. Khasanov ${ }^{1}$
}

${ }^{1}$ Kazan State Medical University, Kazan, Russian Federation

${ }^{2}$ Republican Clinical Hospital of the Ministry of Health of the Republic of Tatarstan, Kazan, Russian Federation

Corresponding author: Eldar Ravilevich Khasanov, haselik1@mail.ru

\begin{abstract}
Introduction There are several options of fixation and plasty for tibial defects. Screw and cement augmentation of the tibia is an alternative to conventional bone autograft and allograft. Although use of metal and cement augments provides reliable support for the tibial plateau and facilitates early weight-bearing on the operated limb the technique fails to maintain enough bone stock for future revisions. The purpose was to present an option of cement and metal augmentation of the tibial component in total knee arthroplasty (TKA). Material and methods The technique consists of cement and screw augmentation using three screws placed vertically as a regular triangle and being perpendicular to the tibial plateau. We describe the technique and a clinical instance of type 2A defect of the proximal tibia using the author's method. Outcome measures were goniometry and radiography. Results Goniometry examination showed positive dynamics in the first week after surgery with flexion of 110.0 degrees, extension 175.0 degrees; at 12 months with flexion of 90.0 degrees and extension of 180.0 degrees. Radiographic examination demonstrated no instability and micromobility of the cement mantle. Discussion The author's technique of screw and cement augmentation of the tibial component was practical for type 2A defects of the proximal tibia with a shortage of materials of bone autografts. This is a pilot study that requires further investigations. Keywords: total knee arthroplasty, tibial plateau defect, grafting, bone cement, screw augmentation
\end{abstract}

For citation: Akhtyamov I.F., Gilmutdinov I.Sh., Khasanov E.R. New option of tibial plateau plasty in total knee arthroplasty (case report). Genij Ortopedii, 2021, vol. 27, no 5, pp. 592-596. https://doi.org/10.18019/1028-4427-2021-27-5-592-596

\section{INTRODUCTION}

Primary arthroplasty of the knee joint is performed at the terminal stages of osteoarthritis which is characterized by the presence of possible defects not only in the cartilaginous layer but also in the subchondral bone. The development of osteoarthritis entails a violation of the subchondral layer remodeling. In the early stages, it leads to degradation of the cartilage and bone tissue resorption, and subsequently to osteogenesis at the bottom of the defect [1-3]. The formation of gross deformities in most cases is associated with the terminal stages of systemic degenerative diseases of the musculoskeletal system (rheumatoid arthritis, ankylosing spondylitis) with cystic remodeling of the epiphysis or with a history of post-traumatic deformities $[4,5]$. The percentage of tibial plateau defects and the total number of knee joint diseases, according to the literature, is about $25-30 \%$ of cases.

The AORI (Anderson Ortopaedic Research Institute) classification developed by G.A. Engh in 1997 has been widely accepted [6]. It characterizes four types of lesions of the condyles of the femur and tibia:

Type 1 - intact bone;

Type $2 \mathrm{~A}$ - affected cancellous bone of one condyle;
Type 2B - symmetrical bone loss in both condyles; Type 3 - cancellous and cortical bone affected.

Orthopedists manage to eliminate most of the deformities when the tibial condyles are cut. However, a number of situations arise when the defect depth is greater than the maximum cut volume. In this case, extended destruction of bone tissue causes difficulties in fixation of the tibial component in knee arthroplasty.

Various options for tibial component fixation in gross deformities of the tibia have been described [4, 5]. Auto- and alloplasty with bone tissue are considered conventional to fill in defects and ensure the correct position of the tibial plateau, and also preserve bone tissue for future revision interventions. However, these methods do not allow early weight bearing and delay rehabilitation. In practice, there are cases when the use of bone grafting is problematic due to tissue deficiency or other features.

This article discusses an alternative author's variant of tibial defects plasty using bone cement with screw reinforcement (RF patent No. 2740467 (2021) [7].

Purpose of the study To present a variant of tibial plateau plasty in knee arthroplasty.

\section{MATERIAL AND METHODS}

The method is used to shape a bed for the tibial component of the prosthesis. Three threaded screws are inserted perpendicular to the axis of the tibial plateau into the area of the defect treated after the cut (Fig. $1 \mathrm{a}$, b) so that the points into which the screws are inserted into the tibia formed a regular triangle (Fig. $1 \mathrm{~d}$ ). The screws are inserted vertically so that their distal ends protrude over the tibial defect, and their caps do not come into contact with the adjacent surface of the tibial component and do not interfere with its installation. The space between the screws and the surface of the cut is filled with bone cement (Fig. $1 \mathrm{c}$ ) 

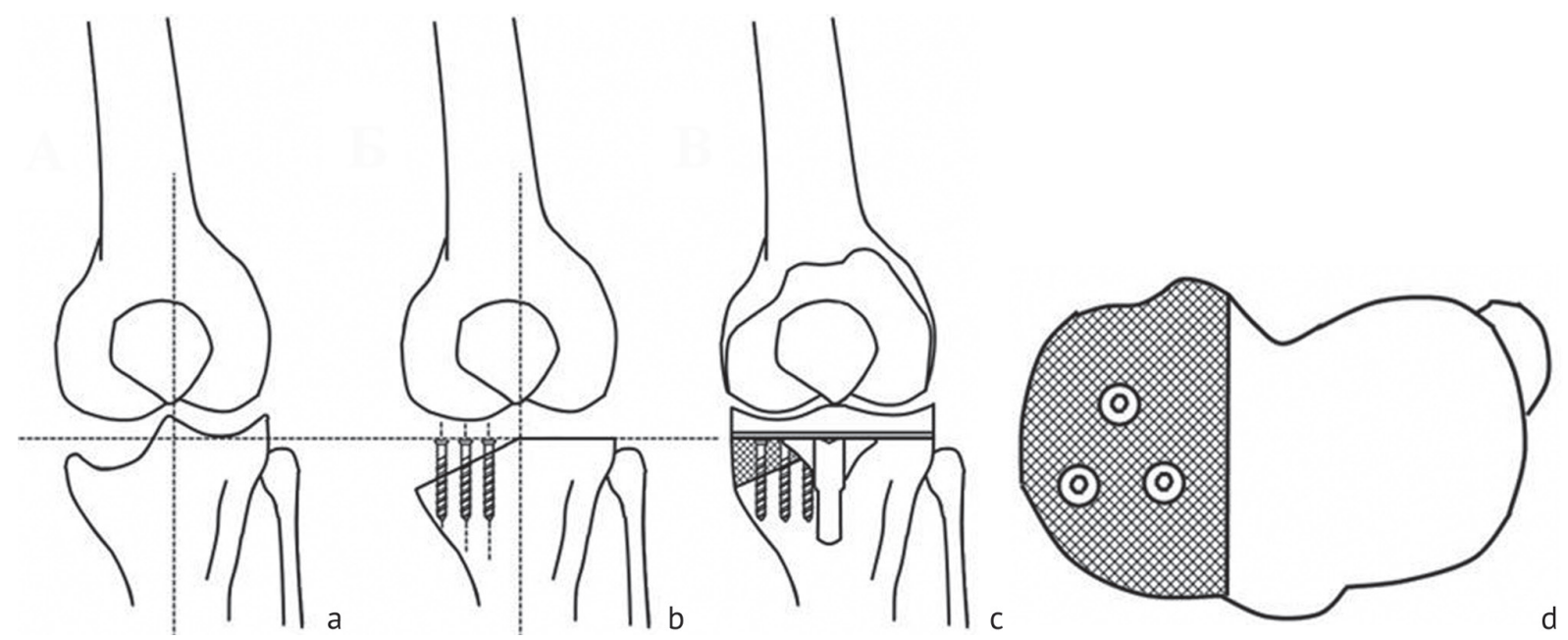

Fig. 1 Diagram of the author's cemented screw fixation variant: $a$ anteroposterior knee joint view with a defect in the tibial plateau; $b$ view of theknee joint after resection of the tibial plateau and inserted screws; $c$ knee joint after installation of the tibial component of the endoprosthesis; $d$ top view of the location of the screw caps in the area of the knee joint defect

The method provides full coverage of the tibial plateau due to the filling of the defect in the tibial condyle with bone cement, prevents the displacement of the cement mantle and the tibial component of the prosthesis due to the reinforcement of bone cement with screws, allows to evenly redistribute the load on the surface of the tibia due to the location of the screws at the base in the form of a regular triangle and their strictly perpendicular arrangement relative to the load plane, and also reduces the risk of developing metallosis due to the lack of contact of the screw heads with the metal tibial component of the prosthesis.

This fixation option allows early loading on the affected leg, which contributes to the restoration of motor actions and walking pattern in the first days after the operation, similar to other plastic methods.

\section{RESULTS}

A case in which this kind of author's method of tibial plateu plasty was used follows.

Patient A.F.G., born in 1958, was admitted to the hospital for grade 3 bilateral gonarthrosis and valgus of the knee joints. In March 2019, total arthroplasty of the left knee joint was performed. During the operation, a marginal defect of the lateral condyle was found, so the main plateau was cut and the oblique defect of the tibia was treated. Three screws were inserted into the area of the marginal defect from top to bottom, the points of insertion into the bone formed a regular triangle, the axis of insertion of each of the screws was perpendicular to the plane of the sawn cut of the main plateau, and their distal parts (caps) were placed $1 \mathrm{~mm}$ below its level (Fig. 2). The space between the screws was filled with bone cement. The tibial component of the endoprosthesis was installed. Then the femoral component of the endoprosthesis and the liner were installed, and the wound was sutured without draining.

After 24 hours, the patient was allowed to load the limb. At follow-up examination after 12 months, the axis of the limb was aligned, the movement in the knee joint was full, and there was no shortening and no pain. It should be noted that the patient had restrictions in the knee joint motion before the operation. Evaluation of goniometry data after surgery showed positive dynamics a year after the intervention (Table 1).

Patient's subjective sensations and X-ray images did not reveal instability and micromobility of the cement mantle (Fig. 3). Figure 3 shows radiographs of the patient with valgus of the left knee joint due to $2 \mathrm{~A}$ tibial defect before and immediately after arthroplasty.

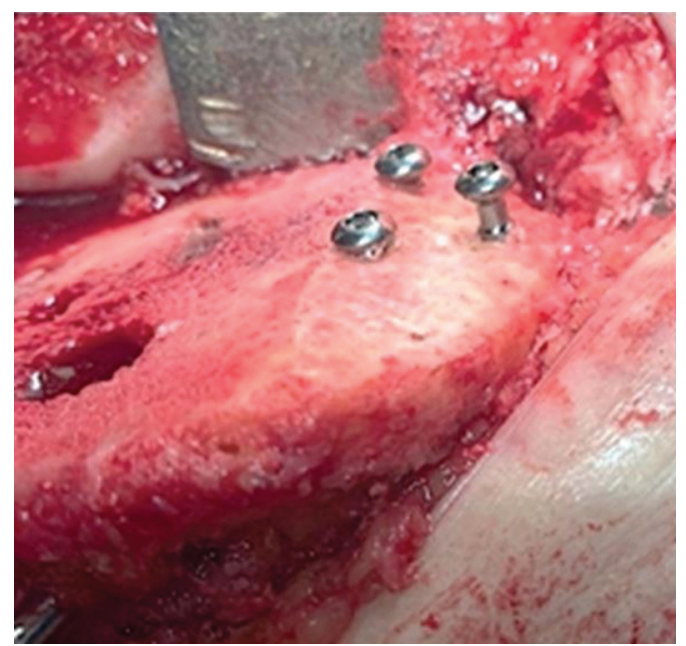

Fig. 2 Location of reinforcement screws the form of a regular triangle points in the tibia defect zone (photo)

Table 1

Dynamics of goniometry indices after knee arthroplasty using the author's method of tibial plateau fixation

\begin{tabular}{|l|c|c|c|}
\hline $\begin{array}{c}\text { Motion } \\
\text { type }\end{array}$ & $\begin{array}{c}\text { Prior to } \\
\text { intervention, }\end{array}$ & $\begin{array}{c}7 \text { days post- } \\
\text { surgery, }\end{array}$ & $\begin{array}{c}12 \text { months } \\
\text { after the } \\
\text { intervention, }\end{array}$ \\
\hline Flexion & 100.0 & 110.0 & 90.0 \\
\hline Extension & 170.0 & 175.0 & 180.0 \\
\hline
\end{tabular}



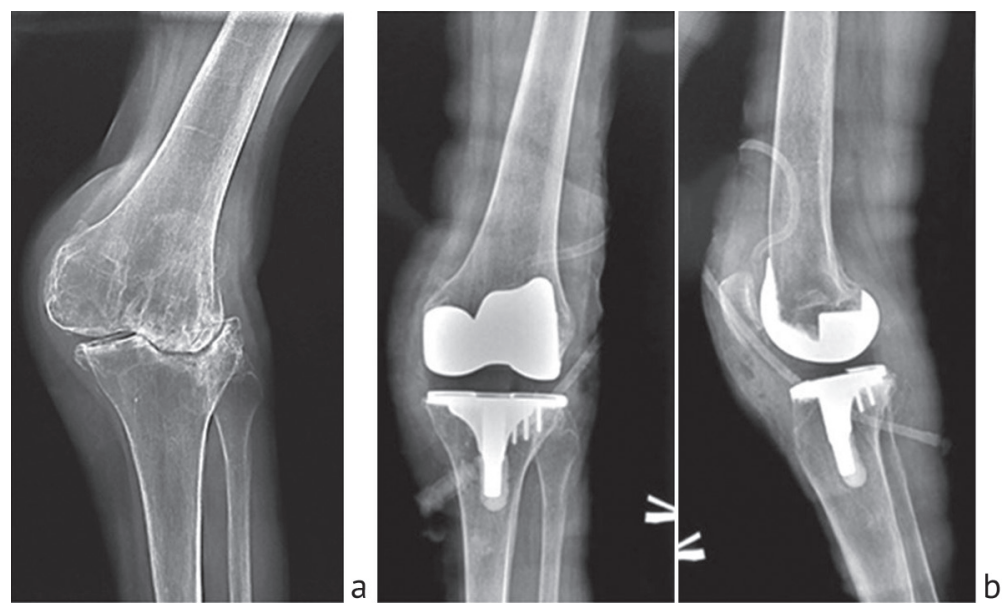

Fig. 3 Radiographs of the left knee joint: $a$ before the intervention, 2A defect and valgus; $b$ immediately after knee arthroplasty with the use of the author's cemented screw fixation of the tibial component

\section{DISCUSSION}

In clinical practice, various methods have been used to repair the defects of the proximal tibia in knee arthroplasty. Each method has its own advantages and disadvantages.

One of the simplest is the method of resection along the defect bottom. The method consists in removing tissue to the maximum at the bottom of destruction. The authors state that this method is unreliable in gross defects even if the maximum size of the liner is used, since the risks of knee instability are very high [5]. It is also worth noting that the strength of the bone tissue decreases in the distal direction. It may also lead to unstable fixation of the component and difficulties in performing revision arthroplasty in the future.

Another option of defect management is bone autoplasty. Cases of using a graft from cuts of a femur or tibia have been described $[5,8-11]$. J.R. Yoon et al. (2017) described positive outcomes of using bone autoplasty for non-isolated 2A defects of the tibia [9]. The average time for consolidation of the graft with the treated proximal tibia was 3.2 months. In view of this fact, it was recommended to limit the axial load on the leg up to 3 months after the operation, what increased the rehabilitation period. The study by T. Sugita et al. (2017) presented the results of a longer observation of the use of bone autogenous graft (on average 58 months after surgery) [10]. The authors described 44 cases of bone grafting in which both cemented and cementless fixation of the tibial components were used. In most cases $(86.4 \%, 38$ out of 44$)$, the bone graft completely united with the bone at 12 months. Japanese orthopedists also described a successful experience of using bone autograft in $98 \%$ of cases (65 out of 66) and one case of failure due to infection [11]. Based on the results of the above works, it can be stated that this method is effective and provides a larger volume of bone tissue for future revision interventions $[5,8-11]$.

The use of cancellous bone allografts is also effective for large defects of the tibia, but complications are more frequent $[5,12]$. A number of authors refer to the plasticity of the material used which enables to adjust the implanted grafts to the size of the defects $[5,12]$. J.C. Ong et al. (2012) performed a comparative analysis of a synthetic bone graft based on calcium carbonate hydroxyapatite and a natural bone graft for tibial plateau defects [13]. The authors concluded that the use of bone allografts is as effective as bone autogenous plasty. However, the use of the method, as well as autogenous plasty, implies adherence to the orthopedic regime associated with limiting the axial load on the limb for 3 months.

There are options for managing bone defects of the tibia with a modular metal block of a wedge- or rectangular shape. The blocks are usually fixed with a screw or bone cement. The advantage of this method is a convenient and fast creation of a reliable support for the tibial component, which facilitates early axial loading on the leg. The disadvantages of this method are a limited size range and shapes of the modules for extensive defects, and difficulties in selection of certain components corresponding to the modules used [5]. S. Tsukada et al. (2013) analyzed 33 knee arthroplasties for varus deformity utilizing metal modules[14]. The authors used rectangular shapes due to their greater stability compared to wedge-shaped ones. The results of a three-year follow-up showed that no subsidence or loosening of the tibial component was observed. However, in $30.3 \%$ of cases ( 10 out of 33 ), there was a rarefaction of bone tissue on the radiographs of the knee joint under the metal block, which in the longer term (after 5-10 years) could lead to instability of the component. The use of wedge-shaped blocks was more successful in the arthroplasty with long-stem components described in the work of X.D. Yun et al (2016) [15]. The use of a metal modules is relevant in cases in which it is not possible to use bone autoplasty, in medium size defects (up to $10 \mathrm{~mm}$ deep) with a preference for a rectangular shape of the module due to possible lateral oblique instability of wedge-shaped ones [5]. 
One of the simplest techniques for extensive bone defects in the tibial department is cementation with methyl methacrylate with screw reinforcement. Among the shortcomings as reported in the literature, are difficulties associated with the pressurization of the bone cement in case of the cortical layer disruption, since the decrease in the height of the cement bed during polymerization can reach $2 \%$ [5]. Due to the possible instability of the component, additional reinforcement with screws arises. Many authors describe positive outcomes of the combined use of methyl methacrylate with screws in the correction of tibial defects [1619]. Y. Liu et al. (2020) evaluated the biomechanical characteristics of a cement-screw rechnique in $2 \mathrm{~A}$ tibial defects [16]. Compared with metal modules, cement-screw fixation reduces the axial impact on the medial region, while the bone could undergo resorption under the metal module, which causes instability of the tibial component. The authors argue that this type of fixation is most consistent with small deformations (up to $5 \mathrm{~mm}$ ). By correcting medium and large defects (more than $10 \mathrm{~mm}$ deep), there was a micromovement of $155 \mu \mathrm{m}$. The location of the screws depended on the size of the defect and the volume of the resection performed. Another group of authors, led by C. Zheng (2020), showed the effectiveness of a cement-screw technique even for large defects (about $20 \mathrm{~mm}$ ) using only two vertically positioned screws [17]. It is in this study that the authors emphasize that the vertical position of the screws ensures greater stability of the tibial component of the endoprosthesis [17]. The vertical position is also the most optimal due to the low risk of osteolysis, what was shown in the study by M. Klutzny et al. (2019). The authors describe a direct correlation of the severity of osteolysis with the size of the angle of screw introduction: the smaller was the angle, the more pronounced was osteolysis [19]. The issue of the number of threaded screws to be inserted to strengthen the structure is controversial. According to the results of the study by C. Zheng et al. (2016) the number of screws used in 40 operations varied from 1 to 6 [20]. However, the authors concluded that the rational selection of the number of screws depends on the size and depth of the defect, as well as on the size of the screws.

Based on our results, it should be noted that the use of methyl methacrylate along with screw reinforcement is an effective method for tibial component fixation, provided that the structure is rationally constructed. Summarizing the data of the cited authors and our own clinical results, we note that the most consistent designs are those with vertical insertion of threaded screws perpendicular to the plateau of the tibial component of the endoprosthesis, since such an arrangement is optimal for supporting axial loads [17]. The results of the work of C. Zheng et al. (2020) proved the vertical position of the screw from a biomechanical point of view. The vertically positioned screw combined with cemented fixation reduces the axial load on the medial part of the tibia by $32 \%$, while the diagonally positioned screw only by $15 \%$ [17]. Thus, fixation with screws inserted horizontally or diagonally relative to the tibial plateau is a less viable option due to a greater risk of micromobility $[16,17]$. It is necessary to use a small number of screws (1-4) in order to preserve a larger volume of bone mass $[17,20]$.

In the clinical case presented above, the location of the screws at the top points of a regular triangle was used. According to the foundations of the supporting structures, such a placement is strong enough due to a uniform distribution of the axial load. The screws, in combination with the bone cement, provide stability for the tibial component of the knee endoprosthesis.

Thus, the proposed method restores the support surface for the tibial component of the endoprosthesis on the tibia plateau, provides strong fixation and alignment.

\section{CONCLUSION}

1. The method proposed is effective in the management of $2 \mathrm{~A}$ defects of the tibia if there is a shortage of autoplasty material.

2. Cemented screw plasty allows for early support load on the affected lower limb, what contributes to faster recovery after surgery.

3. This variant of cemented screw plasty in the clinical case presented achieved positive results. The results obtained require a longer study and a bigger sample size.

\section{REFERENCES}

1. Zhu X., Chan Y.T., Yung P.S.H., Tuan R.S., Jiang Y. Subchondral bone remodeling: a therapeutic target for osteoarthritis. Front. Cell. Dev. Biol., 2021, vol. 8, pp. 607764. DOI: 10.3389/fcell.2020.607764.

2. Aaron R.K., Racine J., Dyke J.P. Contribution of circulatory disturbances in subchondral bone to the pathophysiology of osteoarthritis. Curr. Rheumatol. Rep., 2017, vol. 19, no. 8, pp. 49. DOI: 10.1007/s11926-017-0660-x.

3. Li G., Yin J., Gao J., Cheng T.S., Pavlos N.J., Zhang C., Zheng M.H. Subchondral bone in osteoarthritis: insight into risk factors and microstructural changes. Arthritis Res. Ther., 2013, vol. 15, no. 6, pp. 223. DOI: 10.1186/ar4405

4. Baitov V.S., Gurazhev M.B., Prokhorenko V.M. Autoplastika kostnogo defekta bolshebertsovoi kosti pri pervichnom endoprotezirovanii kolennogo sustava [Autoplasty of the tibia bone defect in primary arthroplasty of the knee]. Sovremennye Problemy Nauki $i$ Obrazovaniia, 2017, no. 6, pp. 19. (in Russian)

5. Kornilov N.N., Kuliaba T.A., Tikhilov R.M., Uazemirskii A.V., Selin A.V., Pechinskii A.I., Petukhov A.I., Kroitoru I.I., Saraev A.V. Zameshchenie kostnykh defektov pri pervichnom endoprotezirovanii kolennogo sustava [Bone defect filling in primary arthroplasty of the knee]. Travmatologiia i Ortopediia Rossii, 2008, no. 1, pp. 76-81. (in Russian)

6. Engh G.A. Bone loss classification. In: Revision Total Knee Arthroplasty. Baltimore, Williams \& Wilkins, 1997, pp. 63-120.

7. Akhtyamov I.F., Gilmutdinov I.Sh., Khasanov E.R. Sposob fiksatsii tibialnogo plato pri endoprotezirovanii kolennogo sustava [The 
way of tibial plateau fixation in the knee athroplasty]. Patent RF no. 2740467, 2020. (in Russian)

8. Akhtyamov I.F., Kuzin V.V., Volodin Iu.S., Shevchenko S.S., Mozdykov A.F. Sposob plastiki defektov bolshebertsovoi kosti [The way of plastic reconstruction of tibial defects]. Patent RF no. 220094, 1999. (in Russian)

9. Yoon J.R., Seo I.W., Shin Y.S. Use of autogenous onlay bone graft for uncontained tibial bone defects in primary total knee arthroplasty. Musculoskelet. Disord., 2017, vol. 18, no. 1, pp. 502. DOI: 10.1186/s12891-017-1826-4.

10.Sugita T., Aizawa T., Miyatake N., Sasaki A., Kamimura M., Takahashi A. Preliminary results of managing large medial tibial defects in primary total knee arthroplasty: autogenous morcellised bone graft. Int. Orthop., 2017, vol. 41, no. 5, pp. 931-937. DOI: 10.1007/ s00264-016-3339-4.

11.Hosaka K., Saito S., Oyama T., Fujimaki H., Cho E., Ishigaki K., Tokuhashi Y. Union, knee alignment, and clinical outcomes of patients treated with autologous bone grafting for medial tibial defects in primary total knee arthroplasty. Orthopedics, 2017, vol. 40, no. 4, pp. e604-e608. DOI: 10.3928/01477447-20170418-01.

12.Totoribe K., Chosa E., Yamako G., Hamada H., Ouchi K., Yamashita S., Deng G. Finite element analysis of the tibial bone graft in cementless total knee arthroplasty. J. Orthop. Surg. Res., 2018, vol. 13, no. 1, pp. 113. DOI: 10.1186/s13018-018-0830-1.

13. Ong J.C., Kennedy M.T., Mitra A., Harty J.A. Fixation of tibial plateau fractures with synthetic bone graft versus natural bone graft: a comparison study. Ir. J. Med. Sci., 2012, vol. 181, no. 2, pp. 247-252. DOI: 10.1007/s11845-011-0797-y.

14.Tsukada S., Wakui M., Matsueda M. Metal block augmentation for bone defects of the medial tibia during primary total knee arthroplasty. J. Orthop. Surg. Res., 2013, vol. 8, pp. 36. DOI: 10.1186/1749-799X-8-36.

15. Yun X.D., An L.P., Jiang J., Yao C.J., Dong H.T., Jin J.X., Xia Y.Y. [Reconstruction of complex proximal tibial defects using the longstem tibial component combined with metallic wedge]. Zhongguo. Gu. Shang., 2016, vol. 29, no. 5, pp. 472-475. (in Chinese)

16.Liu Y., Zhang A., Wang C., Yin W., Wu N., Chen H., Chen B., Han Q., Wang J. Biomechanical comparison between metal block and cement-screw techniques for the treatment of tibial bone defects in total knee arthroplasty based on finite element analysis. Comput. Biol. Med., 2020, vol. 125, pp. 104006. DOI: 10.1016/j.compbiomed.2020.104006.

17.Zheng C., Ma H.Y., Du Y.Q., Sun J.Y., Luo J.W., Qu D.B., Zhou Y.G. Finite element assessment of the screw and cement technique in total knee arthroplasty. Biomed. Res. Int., 2020, vol. 2020, pp. 3710705. DOI: 10.1155/2020/3718705.

18.Liu S., Wang S., Wu T., Fan Z., Zhang Y., Rao Y., Tan M. [Short-term effectiveness of bone cement combined with screws for repairing tibial plateau defect in total knee arthroplasty]. Zhongguo. Xiu. Fu. Chong. Jian. Wai. Ke. Za. Zhi, 2017, vol. 31, no. 9, pp. $1055-1058$. (in Chinese) DOI: 10.7507/1002-1892.201704016.

19.Klutzny M., Singh G., Hameister R., Goldau G., Awiszus F., Feuerstein B., Stärke C., Lohmann C.H. Screw track osteolysis in the cementless total knee replacement design. J. Arthroplasty, 2019, vol. 34, no. 5, pp. 965-973. DOI: 10.1016/j.arth.2018.12.040.

20.Zheng C., Zhou Y.G., Ma H.Y., Zhang Z., Fu H.H., Wu W.M., Piao S., Du Y.Q., Wang S. [Relationship between screw numbers and severity of tibial bone defect in primary total knee arthroplasty]. Zhongguo. Gu. Shang, 2016, vol. 29, no. 5, pp. 415-420. (in Chinese)

The article was submitted 02.03.2021; approved after reviewing 08.06.2021; accepted for publication 23.08.2021.

\section{Information about the authors:}

1. Ildar F. Akhtyamov - Doctor of Medical Sciences, Professor, yalta60@mail.ru;

2. Ildar Sh. Gilmutdinov - M.D., kostolom52@yandex.ru;

3. Eldar R. Khasanov-M.D., haselik1@mail.ru. 